\title{
Clinical characteristics of patients with type 2 diabetes mellitus at the time of insulin initiation: INSTIGATE observational study in Spain
}

\author{
María Costi · Tatiana Dilla · Jesús Reviriego • \\ Conxa Castell · Albert Goday
}

Received: 18 May 2009/Accepted: 28 September 2009/Published online: 24 October 2009

(C) The Author(s) 2009. This article is published with open access at Springerlink.com

\begin{abstract}
Little information is available on the management of patients with type 2 diabetes mellitus (DM2) in regular clinical practice, prior to and at the point of initiating treatment with insulin. The INSTIGATE study provides a description of the clinical profile of the patient with DM2 who begins treatment with insulin in both primary and secondary care. A total of 224 patients who had been diagnosed with DM2, were not responding to oral treatment, and began receiving insulin were included in the INSTIGATE study in Spain. Demographic data were collected, as well as data on macro- and microvascular complications of diabetes and comorbidities, past medical history of diabetes and oral treatment administered, the clinical severity of diabetes (HbAlc concentration) and insulin treatment initiated. Mean age of the sample was 65.4 years and $56.7 \%$ were men. There were $87 \%$ of patients who had a diagnosis of at least one significant comorbidity, notably hypertension and hyperlipidemia. The patient profile for metabolic syndrome was met by $75.1 \%$ of the patients. There was a higher incidence of macrovascular complications $(38.4 \%)$ than microvascular complications $(16.1 \%)$. Prior to insulin initiation, the most recent mean $\mathrm{HbA1c}$ was $9.2 \%$. The majority of patients
\end{abstract}

M. Costi $(\bowtie) \cdot$ T. Dilla $\cdot$ J. Reviriego

Clinical Research Department, Eli Lilly and Company, Avda. de la Industria, 30, 28108 Alcobendas, Madrid, Spain

e-mail: costi_maria@lilly.com

C. Castell

Division of Public Health, Department of Health, Generalitat of Catalonia, Barcelona, Spain

A. Goday

Servicio de Endocrinología, Hospital del Mar,

Universidad Autónoma de Barcelona, Barcelona, Spain had been treated in the last 12 months with sulfonylureas and/or metformin (69.6 and 57.6\%). The most common treatment prior to insulinization was the co-administration of two oral antidiabetics (OADs) (37.5\%). Patients with DM2 observed in the study presented with elevated mean HbA1c and body mass index levels, comorbidities and complications related to diabetes at the time of insulin initiation. Changes and adjustments in treatment from diagnosis of diabetes occur when HbAlc levels are far above those recommended by the IDF (International Diabetes Federation), a factor which could be contributing to the development of both macrovascular and microvascular complications in the patient profile described in the study.

Keywords Type 2 diabetes mellitus - Epidemiology · Treatment $\cdot$ Spain

\section{Introduction}

Type 2 diabetes mellitus (DM2) is a chronic disease that is becoming increasingly prevalent in Western populations. At the beginning of the 1990s, it was estimated that global prevalence would increase by around $40 \%$ over the following 10 years, rising from approximately 150-210 million patients [1]. In the absence of adequate glucose control, patients with DM2 present a higher risk of developing macrovascular as well as microvascular complications [2]. The high prevalence and incidence of DM2, including the associated increased morbidity and premature mortality, make diabetes a major pressure on health resources [3].

In Spain, diabetes mellitus is one of the main causes of mortality, ranking third place for women [4]. The prevalence estimations for DM2 in Spain vary between 4.8\% [5] and $18.7 \%$ [6], with an annual incidence between 8.2 [7] 
and 10.8 cases [8] per 1,000 people. It has been suggested that more than one-third of people with diabetes in Spain have not been diagnosed [9].

The International Clinical Guidelines for the management of glucose control in patients with type 2 diabetes published by the International Diabetes Federation (IDF) recommend implementing changes in the lifestyle of the patient, followed by different treatment patterns, ranging from a single oral antidiabetic drug (OAD) to a combination of oral agents ending up with insulin treatment, always with the objective of maintaining the HbA1c level under $6.5 \%$ [10]. In the observation of daily clinical practice, insulin initiation for patients is sometimes delayed due to the potential risk of hypoglycemia, the need to educate patients on the use of insulin, the need to increase glucose control and concern over weight gain [11].

Studies were conducted in the past that describe the pattern of oral antidiabetic and insulin use. These provide data on the level of glucose control achieved with each of these treatments, individually or combined, at different stages of the disease, the development of complications associated with DM2, the duration of therapy for each defined treatment pattern and clinical variables at the time the medication was changed [12-15].

However, the information provided by these studies needs to be updated, since in recent years, significant innovations have appeared within drug treatment options for DM2. In addition, the clinical guidelines for glucose control in type 2 diabetes published by the IDF have recently been reviewed, updating both the recommendations on glucose [10] and metabolic control [16], and the definition of the profile of patients with metabolic syndrome [17]. Therefore, describing treatment patterns in clinical practice and evaluating the proportion of patients who comply with the recommendations of these international guidelines appear to be of major importance in the management of patients with DM2, allowing the implementation of initiatives that improve compliance and thus the clinical situation of the patients.

The present study describes the clinical profile of the DM2 patient who begins insulin treatment in primary and/or secondary care.

\section{Methods}

The present work was conducted with baseline data, relating to a Spanish sample in the European non-interventional, multicenter, prospective, observational INSTIGATE study, in which we provide a description of the profile of the DM2 patient who begins insulin treatment in primary and/or secondary care in Spain. The study was designed to determine the direct costs associated with the first 24 months of insulin treatment in patients with DM2 and to describe the utilization of resources, the quality of metabolic control and the associated clinical results. This study included patients with DM2 who began treatment with insulin because they did not have acceptable glucose control levels according to clinical judgement and who granted their informed consent. In addition to the baseline data published for the whole European sample [18], the present paper allows a closer look at the Spanish patients within the study, especially in relation to comorbidities at the time of insulin initiation, and treatment patterns before and at the point of initiation of insulin therapy and provides the opportunity to put the data in context within a Spanish environment.

Sites were selected so that the geographic distribution and investigator type (general practitioner or specialist) were representative of the physician population treating patients with type 2 diabetes both up to and through the insulin initiation process. Specialist secondary care centers that did not care for the entire spectrum of patients with diabetic were not included, as these patients were less likely to be representative of the usual patient initiating insulin in Spain.

The participating investigators identified patients with DM2 who (1) began treatment with insulin at that visit to the doctor's office or (2) were promptly sent by the primary care physician to a specialist so that insulin treatment could be initiated, continuing their clinical follow-up at the primary care office.

At the initial visit of this study, the following data were collected:

1. Demographic and anthropometric characteristics of the patient: age, sex, ethnic identity, smoking status, height, weight and waist circumference.

2. Presence of medical complications: coronary disease, stroke, occlusive peripheral artery disease, congestive heart failure, diabetic retinopathy, diabetic nephropathy, diabetic neuropathy, amputation of any limb, hypertension, hyperlipidemia, depression, cancer and other comorbidities.

3. Past medical history of diabetes: date of diagnosis, treatment patterns prior to insulin initiation (duration and type of therapy) and OAD drugs (generic name, dose, frequency, start date and end date and the reason for discontinuation) taken during the 12 months prior to insulin initiation.

4. Clinical severity: based on HbA1c levels, lipid profile, fasting plasma glucose and blood pressure.

5. Insulin treatment: description of insulin treatment initiated at the beginning of the study.

As INSTIGATE is an observational study, results were obtained from the medical records and supported by the clinical judgement of the investigators. All data were 
provided as they were generated in usual care and no additional visits, tests or interventions were required as part of the study protocol.

Data on HbA1c (\%), lipids (HDL-cholesterol LDLcholesterol and triglycerides) and blood pressure of each eligible patient were compared with the levels recommended by the IDF to determine what proportion of the Spanish population in the study was achieving target. The following are the current recommended targets:

- HbA1c $<6.5 \%$

- Lipids: HDLc $>39 \mathrm{mg} / \mathrm{dL}, \quad$ LDLc $<95 \mathrm{mg} / \mathrm{dL}$ and triglycerides $<200 \mathrm{mg} / \mathrm{dL}$

- Blood pressure $<130 / 80 \mathrm{mmHg}$ [16].

Data on waist circumference, triglyceride level, HDLc, blood pressure and fasting blood glucose levels were used to

Table 1 Patient characteristics

\begin{tabular}{lcr}
\hline Parameter & Mean (SD) & $n$ \\
\hline Weight $(\mathrm{kg})$ & $77.72(15.67)$ & 224 \\
Body mass index $\left(\mathrm{kg} / \mathrm{m}^{2}\right)$ & $29.54(5.50)$ & 224 \\
Abdominal perimeter $(\mathrm{cm})$ & $99.9(16.57)$ & 224 \\
Men $(\mathrm{cm})$ & $101.9(15.32)$ & 127 \\
Women $(\mathrm{cm})$ & $97.3(17.81)$ & 97 \\
Systolic blood pressure (mmHg) & $137.1(18.35)$ & 216 \\
Diastolic blood pressure (mmHg) & $78.6(10.79)$ & 216 \\
HDLc (mg/dL) & $49.30(15.07)$ & 209 \\
LDLc (mg/dL) & $108.04(37.28)$ & 208 \\
Triglycerides (mg/dL) & $173.7(98.55)$ & 215 \\
HbA1c at diagnosis $(\%)$ & $8.23(1.88)$ & 49 \\
Time since first diagnosed (years) & $10.26(7.14)$ & 220 \\
Current smokers $[n(\%)]$ & $22(9.8 \%)$ & 224 \\
\hline
\end{tabular}

The results are presented as mean results (standard deviation) except for the percentage of smokers evaluate the proportion of patients from the Spanish sample who met the criteria for the diagnosis of metabolic syndrome according to the guidelines published by the IDF [17].

For a patient to be diagnosed with metabolic syndrome, in accordance with the definition by the IDF, European men must have a waist circumference $\geq 94 \mathrm{~cm}$ and European women $\geq 80 \mathrm{~cm}$ and, at least two of the following factors:

1. An elevated triglyceride level: $\geq 150 \mathrm{mg} / \mathrm{dL}$ or a treatment specific to this lipid abnormality.

2. Reduced HDLc level: $<40 \mathrm{mg} / \mathrm{dL}$ in men and $<50 \mathrm{mg} / \mathrm{dL}$ in women or a specific treatment for this lipid abnormality.

3. Raised systolic blood pressure $\geq 130 \mathrm{mmHg}$ or diastolic blood pressure $\geq 85 \mathrm{mmHg}$ or treatment for previously diagnosed hypertension.

4. Raised blood glucose level: fasting blood glucose $\geq 100 \mathrm{mg} / \mathrm{dL}$ or previously diagnosed with DM2.

Statistical analysis

The variables from the study on the demographic, clinical and treatment characteristics were analyzed using descriptive statistics: mean, standard deviation, median, minimum and maximum for quantitative variables and relative and absolute frequencies for qualitative variables. If not stated otherwise, percentages are based on the number of eligible patients. All analyses were conducted using SAS software version 8.2.

\section{Results}

The results refer to the 224 patients included in the INSTIGATE study in Spain, by 24 investigators (9
Fig. 1 Evaluation of the clinical severity of diabetes through HbA1c measurement prior to insulin initiation

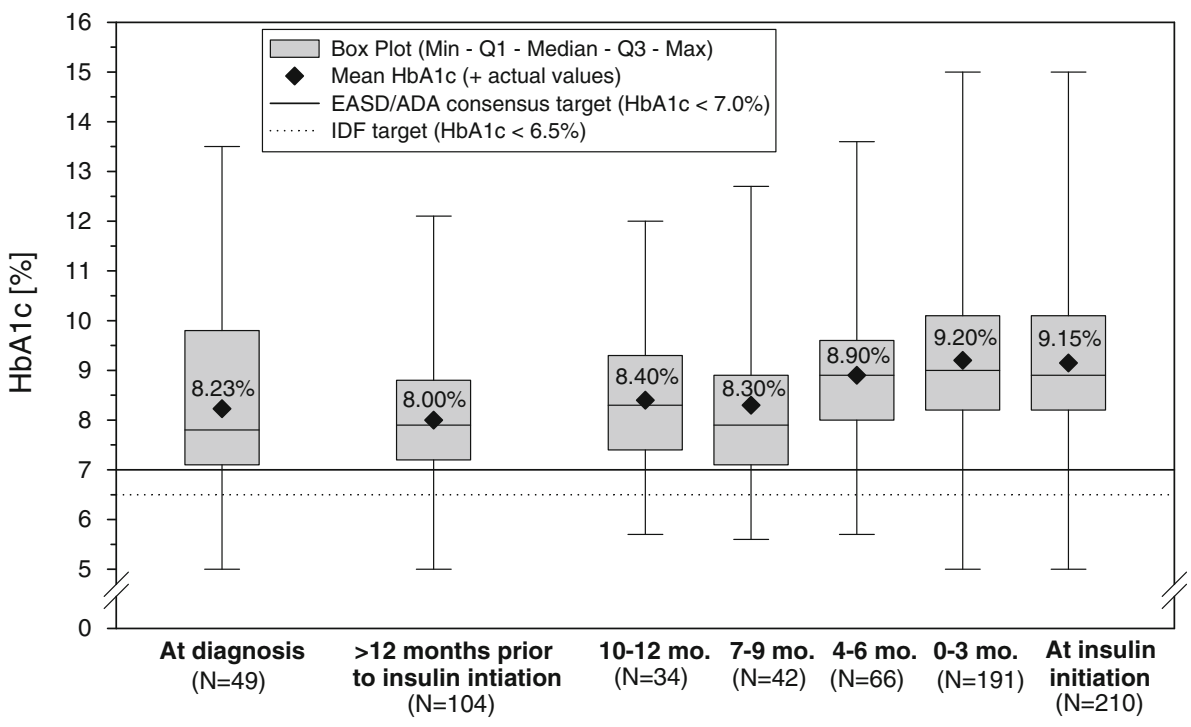


Fig. 2 Data on the percentage of patients who meet the criteria for the diagnosis of metabolic syndrome and therapeutic outcomes defined by the IDF. Percentages are based on the number of patients evaluable for the respective criterion

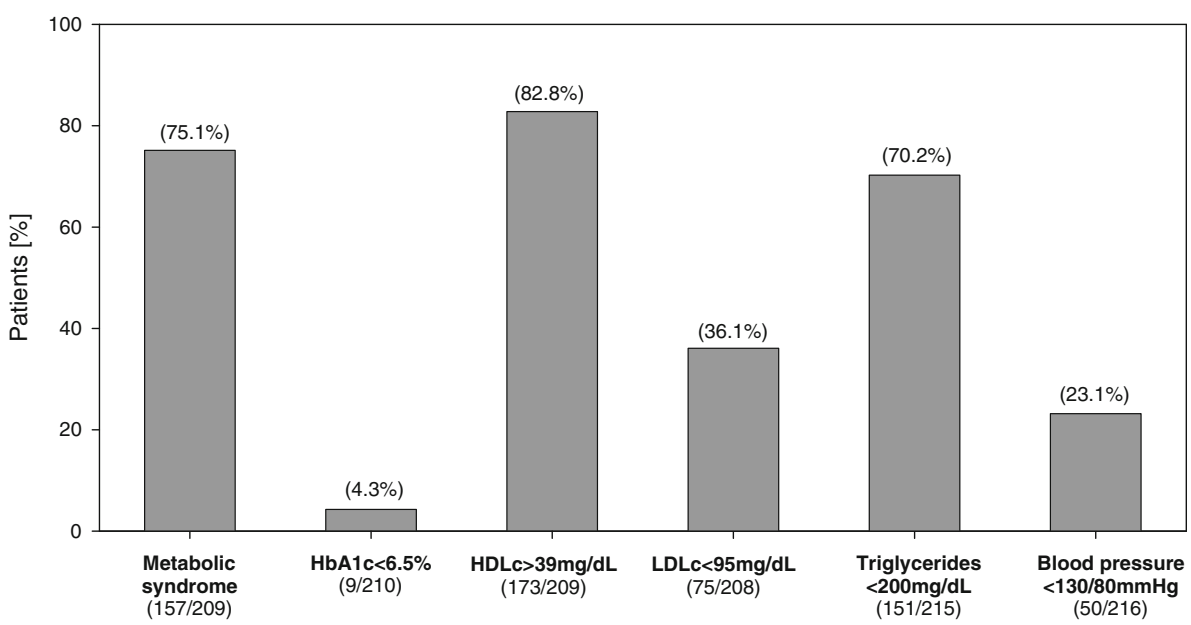

endocrinologists, 8 internal medicine specialists and 7 primary care physicians) at the point of insulin initiation.

The majority of the patients were men $(56.7 \%)$, Caucasian $(97.8 \%)$, with a mean age of $65.4(\mathrm{SD}=12.1)$ years, with women being older, 67.2 (11.5) than men, 64.1(12.5). The principal patient characteristics are presented in Table 1.

Of the total patient population, $36 \%$ were overweight $(25 \leq \mathrm{BMI}<30)$ and $43.3 \%$ were obese $(\mathrm{BMI} \geq 30)$. Women presented a more elevated mean BMI value than men [30.56 (6.36) vs. 28.77 (4.63) kg/m², respectively]. Clinical severity was evaluated through HbA1c measurement. Mean HbA1c at diagnosis of the disease and 12 months prior to insulinization were much higher than the glucose control targets recommended by the IDF, reaching a value of $9.2 \%$ prior to insulin initiation (Fig. 1). There were a few patients $(n=9)$ who presented HbA1c values below $6.5 \%$ at insulin initiation who may have started this treatment due to other clinical factors or comorbidities where clinical judgment advised tight glucose control. Patients with $\mathrm{HbA} 1 \mathrm{c}>8.0 \%$ versus patients with $6.5 \%<\mathrm{HbA} 1 \mathrm{c} \leq 8.0 \%$ had higher rates of chronic complications ( 88.0 vs. $82.4 \%$, respectively). In addition, patients who had at least one macrovascular complication had higher mean values of HbA1c \% (9.29\%) than those who did not $(8.94 \%)$.

Figure 2 presents the percentage of eligible patients who meet the therapeutic goals established by the IDF, with respect to lipid values (LDLc, HDLc and triglycerides), blood pressure, and $\mathrm{HbA} 1 \mathrm{c}$ concentration and the criteria for diagnosis of metabolic syndrome.

For the diagnosis of metabolic syndrome at baseline, a smaller sample $(n=209)$ than that included in the study was evaluated, due to the absence of at least one data element necessary for this evaluation for some patients.

There were $75.1 \%$ of evaluable patients who met the patient profile for metabolic syndrome, $95.7 \%$ who
Table 2 Comorbidity incidence in patients at the time of insulin initiation $(n=224)$

\begin{tabular}{lc}
\hline Comorbidity & $\begin{array}{c}n(\%) \text { of patients } \\
\text { with comorbidity }\end{array}$ \\
\hline Macrovascular complications (at least 1) & $86(38.4)$ \\
Coronary disease & $49(21.9)$ \\
Stroke & $18(8.0)$ \\
Transient ischemic attack & $10(4.5)$ \\
Peripheral occlusive arterial disease & $13(5.8)$ \\
Congestive heart failure & $24(10.7)$ \\
Amputation & $2(0.9)$ \\
Microvascular complications (at least 1$)$ & $36(16.1)$ \\
Diabetic retinopathy & $15(6.7)$ \\
Diabetic nephropathy & $23(10.3)$ \\
Diabetic neuropathy & $9(4.0)$ \\
Other comorbidities (at least 1) & $182(81.3)$ \\
Hypertension & $137(61.2)$ \\
Hyperlipidemia & $111(49.6)$ \\
Depression & $29(12.9)$ \\
Cancer & $12(5.4)$ \\
Others & $48(21.4)$
\end{tabular}

presented an unacceptable $\mathrm{HbA1c}$ concentration level $(>6.5 \%)$ and $63.9 \%$ who presented an LDLc level higher than the clinical recommendation $(95 \mathrm{mg} / \mathrm{dL})$.

The majority of the population studied $(87 \%)$ presented with at least one significant comorbidity, $38.4 \%$ had macrovascular complications and $16.1 \%$ microvascular complications (Table 2). Coronary disease was the most frequent macrovascular complication followed by congestive heart failure; with respect to microvascular complications, diabetic nephropathy was more frequent than retinopathy or neuropathy in the sample studied.

In regard to oral treatment during the 12 months prior to insulin initiation, the majority of the patients had received 


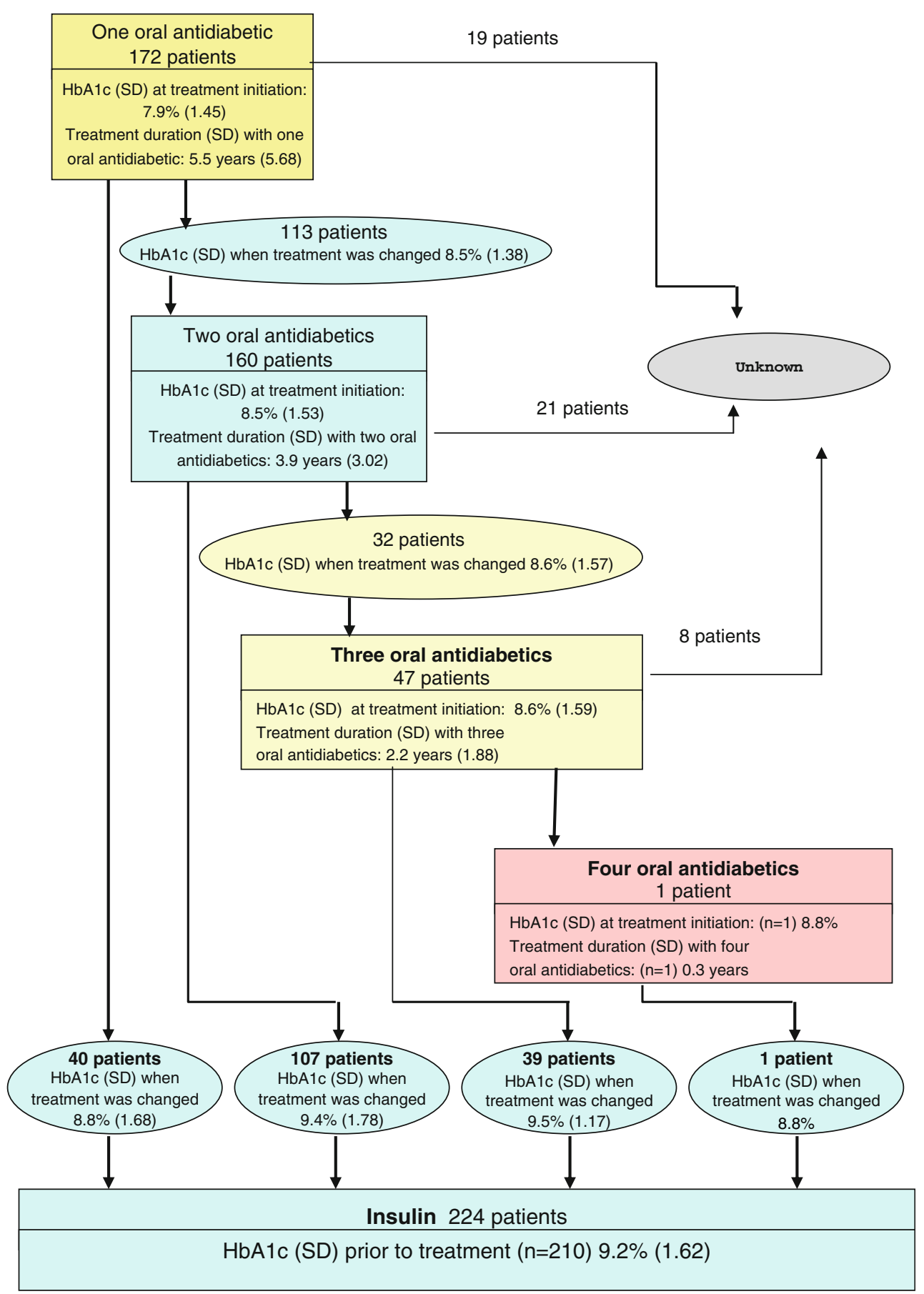

Fig. 3 Different treatment patterns for DM2 before insulinization

sulfonylureas (156 patients; 69.6\%) and/or metformin (129 patients; $57.6 \%$ ) and to a lesser degree, thiazolidinediones (33 patients; 14.7\%), alpha-glucosidase inhibitors (29 patients; 12.9\%), meglitinides (36 patients; 16.1\%) and other drugs (6 patients; $2.7 \%$ ).

In the period between being diagnosed with DM2 and insulin initiation, $39.5 \%$ of the patients had modified their treatment patterns progressing from 1 to 2 OADs prior to insulin initiation, $17.9 \%$ had received only single OAD therapy prior to insulin, $11.2 \%$ had progressed from 1 to 2 then 3 OADs, $8.5 \%$ had received only dual therapy with OADs, 9.4\% did not know the antidiabetic treatment history and $6.3 \%$ of the patients had not been treated with OADs. Figure 3 presents the different patterns followed in 
Table 3 Treatment patterns of insulin initiation

\begin{tabular}{lcclll}
\hline Initial administration of insulin & $n$ & $\begin{array}{l}\text { Percentage } \\
\text { of patients }\end{array}$ & $\begin{array}{l}\text { Mean number } \\
\text { of injections }\end{array}$ & $\begin{array}{l}\text { Mean daily } \\
\text { dose (IU) }\end{array}$ & $\begin{array}{l}\text { Mean daily dose } \\
\text { (IU)/kg of weight }\end{array}$ \\
\hline Basal & 135 & 60.3 & 1.1 & 16.9 & 0.23 \\
Pre-established mixtures & 42 & 18.8 & 2.0 & 29.9 & 0.37 \\
Only rapid & 21 & 9.4 & 2.5 & 23.6 & 0.34 \\
Basal/bolus & 4 & 1.8 & 2.5 & 24.0 & 0.36 \\
Other & 2 & 0.9 & 1.0 & 15.33 & 0.21 \\
Basal and mixed & 1 & 0.4 & 2.0 & 24.0 & - \\
Unknown & 19 & 8.5 & - & - & - \\
Total & 224 & 100 & - & 20.0 & - \\
\hline
\end{tabular}

the treatment prior to insulin initiation, demonstrating the mean HbA1c at the time of change in therapy and the duration of treatment on each therapy.

Table 3 describes the insulin regimen initially prescribed for the subjects studied. The most common insulin treatment was a basal insulin only, which was received by $60.3 \%$ of the subjects.

\section{Discussion}

The results of the current study suggest patients with DM2 initiating treatment with insulin in Spain are on average aged 65, have had a diagnosis of DM2 for around 10 years and are likely to be overweight or obese. Figure 1 indicates that the majority of patients $(>75 \%)$ had HbAlc values higher than those recommended by the IDF during the year prior to initiation of insulin. These results are supported by several studies $[15,19,20]$, which have evidenced that only a small proportion of patients with diabetes achieve therapeutic objectives in relation to metabolic control, in spite of a number of publications in recent years manifesting the importance of attaining a good control to prevent or delay the development of complications associated with DM2 $[12,13,16]$.

The majority of evaluable patients from the INSTIGATE study met the criteria for the diagnosis of metabolic syndrome. These patients are estimated to present twice the risk of mortality and three times the risk of cardiovascular disease, compared to healthy individuals [21].

Glucose control strategies and recommendations on $\mathrm{HbA} 1 \mathrm{c}$ targets are currently under discussion since findings from recently published trials, such as ACCORD, ADVANCE and VADT have not demonstrated a significant reduction in cardiovascular disease with intensive glycemic control [22, 23]. However, conversely, the 10-year follow-up data of the UKPDS study did show a reduction in myocardial infarction and all-mortality cause associated to intensive glucose lowering [24].
With regard to treatment patterns followed by patients in the INSTIGATE study, the changes in treatment occurred when the mean HbAlc value was at least $8.5 \%$, which is well above the levels recommended by the IDF guidelines [10] and the consensus treatment algorithm developed by the ADA (American Diabetes Association) in collaboration with the EASD (European Association for the Study of Diabetes) [25]. In addition, at insulin initiation, mean HbA1c was very high (9.15\%). Mean HbA1c was lower for patients with one oral antidiabetic than for patients with two or more oral antidiabetics as their immediate previous treatment (Fig. 3).

A limitation of the INSTIGATE study is that although patients were included in a prospective manner from the time of insulin initiation, part of the data collection was retrospective, and obtained from the clinical history. Due to the fact that it was an observational study, all results were provided as they were generated in usual care, and therefore the values of $\mathrm{HbA} 1 \mathrm{c} \%$ and other lab results were not standardized. Statistical analysis comparing patients from various settings were not carried out since it was not a specified objective of the study to look at possible differences between patients being treated in primary and secondary care. However, this could be an interesting analysis to consider for future studies. Finally, it is possible that a very small number of patients included in the study could have had undiagnosed LADA (Latent Autoimmune Diabetes of the Adult) with an incorrect diagnosis of type 2 diabetes. Given the observational nature of the study, no additional tests could have been run to confirm diabetes type.

The baseline data for the Spanish sample of the INSTIGATE study demonstrate that initiation of insulin therapy in patients with DM2 occurs only after patients have had poor glycemic control for a sustained period of time (Fig. 1). Due to the high prevalence of cardiovascular risk factors and comorbidities related to diabetes, we can consider the studied patients are at high risk of cardiovascular disease and associated mortality. It appears, 
therefore, that more needs to be done to encourage earlier intervention to intensify therapy, in accordance with current recommendations for the treatment of DM2, with the final objective of achieving more effective glucose control, and ultimately avoiding or delaying the development of complications associated with diabetes, a cause of high morbidity and mortality in patients with DM2.

Acknowledgments This study has been funded by Eli Lilly. We acknowledge the contributions made by Helen Smith assisting with the crucial review of this manuscript and by Claudia Nicolay responsible for the statistical analysis of the INSTIGATE study.

Open Access This article is distributed under the terms of the Creative Commons Attribution Noncommercial License which permits any noncommercial use, distribution, and reproduction in any medium, provided the original author(s) and source are credited.

\section{References}

1. Zimmet PZ (1999) Diabetes epidemiology as a tool to trigger diabetes research and care. Diabetologia 42:499-518

2. Stratton IM, Adler AI, Neil HA, Matthews DR, Manley SE, Cull CA et al (2000) Association of glycemia with macrovascular and microvascular complications of type 2 diabetes (UKPDS 35): prospective observational study. BMJ 321:405-412

3. Ettaro L, Songer TJ, Zhang P, Engelgau MM (2004) Cost-ofillness studies in diabetes mellitus. Pharmacoeconomics 22:149164

4. Ruiz-Ramos M, Escolar-Pujolar A, Mayoral-Sánchez E, CorralSan Laureano F, Fernández-Fernández I (2006) La diabetes mellitus en España: mortalidad, prevalencia, incidencia, costes económicos y desigualdades. Gac Sanit 20(suppl 1):15-24

5. Servicio Andaluz de Salud (1993) Estudio DRECA: dieta y riesgo de enfermedades cardiovasculares en Andalucía, Sevilla: Consejería de Salud. http://www.juntadeandalucia.es/ servicioandaluzdesalud/publicaciones/

Listadodeterminado.asp?idp=114. Accessed 12 May 2009

6. De Pablos-Velasco PL, Martínez-Martín FJ, Rodríguez Pérez F et al (1997) Prevalence and determinants of diabetes mellitus and glucose intolerance in a Canarian Caucasian population. Comparison of the 1997 ADA and the 1985 WHO criteria. The Guia Study. Diabet Med 18:235-241

7. Vázquez JA, Gaztambide S, Soto-Pedre E (2000) Estudio prospectivo a 10 años sobre la incidencia y factores de riesgo de diabetes mellitus tipo 2. Med Clin (Barc) 115:534-539

8. Valdés S, Botas P, Delgado E, Alvarez F, Cadórniga FD (2007) Population-based incidence of type 2 diabetes in northern Spain: the Asturias Study. Diabetes Care 30(9):2258-2263

9. Sender MJ, Vernet M, Larrosa P, Tor E, Foz M (2002) Características sociodemográficas y clínicas de una población de pacientes con diabetes mellitus. Aten Primaria 29(8):474-480

10. The International Diabetes Federation (IDF) (2005) Global guidelines for type 2 diabetes, chap 6. Glucose control levels. http://www.idf.org/home/index.cfm?node=1457. Accessed 12 May 2009

11. Wright A, Burden ACF, Paisey RB, Cull CA, Holman RR (2002) Sulfonylurea inadequacy. Efficacy of addition of insulin over
6 years in patients with type 2 diabetes in the UK. Prospective diabetes study (UKPDS 57). Diabetes Care 25:330-336

12. Shichiri M, Kishikawa H, Ohkubo Y, Wake N (2000) Long-term results of the Kumamoto Study on optimal diabetes control in type 2 diabetic patients. Diabetes Care 23(suppl 2):B21-B29

13. The Diabetes Control and Complications Trial Research Group (1993) The effect on intensive treatment of diabetes on the development and progression of long-term complications in insulin-dependent diabetes mellitus. N Engl J Med 329:977-986

14. UK Prospective Diabetes Study (UKPDS) Group (1998) Intensive blood-glucose control with sulphonylureas or insulin compared with conventional treatment and risk of complications in patients with type 2 diabetes (UKPDS 33). Lancet 352(9131): 837-853

15. Rae N, Secnik K, Dilla T, Lara N, Badía X (2008) Physician and patient management of type 2 diabetes and factors related to glycemic control in Spain. Patient Prefer Adherence 2:87-95

16. Cardiovascular Risk Protection (2005) The International Diabetes Federation (IDF). Global Guidelines for type 2 diabetes, chap 12. http://www.idf.org/home/index.cfm?node=1457. Accessed 12 May 2009

17. The IDF Worldwide Definition of the Metabolic Syndrome (2006) The International Diabetes Federation (IDF). http://www. idf.org/home/index.cfm?node=1429. Accessed 12 May 2009

18. Jones S, Benroubi M, Castell C, Goday A, Liebl A, Timlin L, Nicolay C, Simpson A, Tynan A (2009) Characteristics of patients with type 2 diabetes mellitus initiating insulin therapy: baseline data from the INSTIGATE study. Curr Med Res Opin. 30 Jan 2009. [Epub ahead of print]

19. Gaede P, Lund-Andersen H, Parving HH, Pedersen O (2008) Effect of a multifactorial intervention on mortality in type 2 diabetes. N Engl J Med 358(6):580-591

20. Adler AI, Stratton IM, Neil HA, Yudkin JS, Matthews DR, Cull CA, Wright AD, Turner RC, Holman RR (2000) Association of systolic blood pressure with macrovascular and microvascular complications of type 2 diabetes (UKPDS 36): prospective observational study. BMJ 321(7258):412-419

21. Saydah SH, Fradkin J, Cowie CC (2004) Poor control on risk factors for vascular disease among adults with previously diagnosed diabetes. JAMA 291:335-342

22. Gerstein HC, Miller ME, Byington RP et al (2008) Effects of intensive glucose lowering in type 2 diabetes. $\mathrm{N}$ Engl $\mathrm{J}$ Med 358:2545-2559

23. Skyler JS, Bergenstal R, Bonow RO et al (2009) American Diabetes Association; American College of Cardiology Foundation; American Heart Association. Intensive glycemic control and the prevention of cardiovascular events: implications of the ACCORD, ADVANCE, and VA diabetes trials: a position statement of the American Diabetes Association and a scientific statement of the American College of Cardiology Foundation and the American Heart Association. Circulation 20;119(2):351-357

24. Holman RR, Paul SK, Bethel MA, Matthews DR, Neil HA (2008) 10 -year follow-up of intensive glucose control in type 2 diabetes. N Engl J Med 359(15):1577-1589

25. Nathan DM, Buse JB, Davidson MB, Ferrannini E, Holman RR, Sherwin R, Zinman B (2009) American Diabetes Association; European Association for Study of Diabetes. Medical management of hyperglycemia in type 2 diabetes: a consensus algorithm for the initiation and adjustment of therapy: a consensus statement of the American Diabetes Association and the European Association for the Study of Diabetes. Diabetes Care 32(1):193203 